Brit. J. vener. Dis. (1957), 33, 246.

\title{
TWO CASES OF PERINEAL FISTULA FOLLOWING COWPERITIS*
}

\author{
BY \\ M. A. BIRNSTINGL, J. D. GRIFFITHS, C. S. NICOL, AND A. REDMOND \\ Departments of Venereology and Surgery, St. Bartholomew's Hospital, London
}

Before the use of chemotherapy and antibiotics, acute and chronic inflammation of Cowper's glands was a fairly common complication of gonorrhoea and non-gonococcal urethritis. These conditions were well reviewed by Harkness (1937), but they are now relatively uncommon. The following two cases were seen in the Special Treatment Centre at St. Bartholomew's Hospital. In both cases, fistulae existed in the perineum connecting Cowper's gland with a cutaneous opening, and in one case an urethral fistula was also present.

\section{Case Reports}

Case 1, a West Indian aged 29 years, was seen in the Out-Patient Department with an abscess in the perineum.

* Received for publication June 17, 1957.
He gave a history of having had gonorrhoea 10 years previously. This was treated with penicillin, but no final tests of cure were done.

A year earlier he had attended another hospital with a similar swelling in the perineum. The posterior urethra and the periurethral tissue was found to be tender and indurated; all tests were negative and a diagnosis of old periurethritis was made. He was given streptomycin $1 \mathrm{~g}$. intramuscularly daily for 5 days and prostatic massage weekly for 3 weeks. The inflammation subsided and left a tender swelling in the region of Cowper's gland about the size of a walnut.

He had no further treatment until seen in the OutPatient Department of this hospital with a large abscess posterior to the scrotum which was incised. A persistent sinus developed and a swab taken from the pus showed organisms sensitive to oxytetracycline; a course of this drug was given, with no improvement.

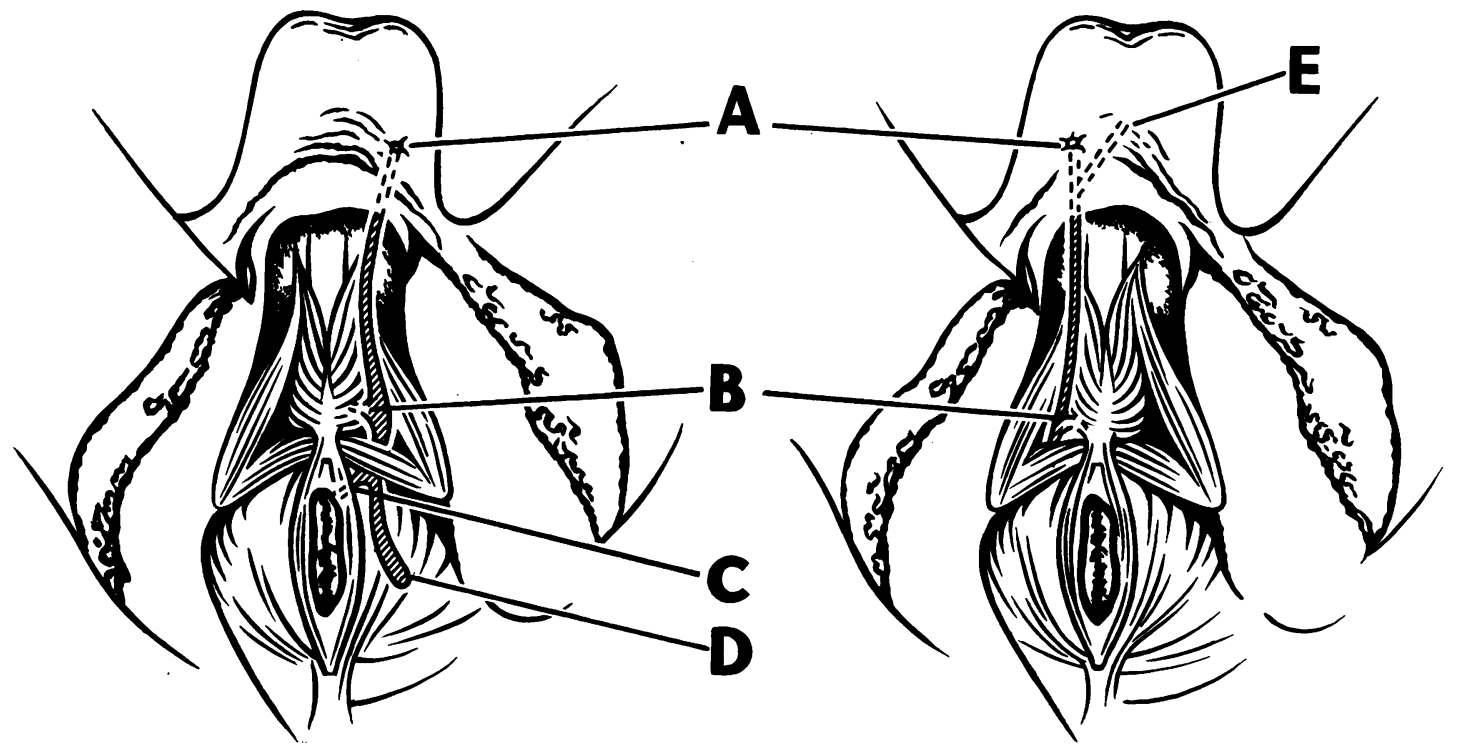

(a)

Fig. 1.-Diagrammatic representation of fistula of Case 1 as seen at operation. A, external opening; B, site at which tract passes through perineal membrane; $\mathrm{C}$, posterior projection of fistula; $\mathrm{D}$, blind tract in ischio-rectal fossa; $\mathrm{E}$, urethral fistula. 
There was no urethral discharge, the urine was sterile, and the Wassermann reaction and Kahn and gonococcal complement-fixation tests were negative. The complement-fixation test for lymphogranuloma venereum and the Frei test were both negative. It was decided to admit this patient for excision of the fistula. While awaiting admission he had an exacerbation of the cowperitis.

On examination affer admission to hospital, there was no evidence of any disease other than the discharging sinus in the perineum. The opening was small and situated on the left side on the posterior scrotal wall near its junction with the perineum. An indurated track could be felt in the perineal space running backwards to the anal margin. A probe could easily be passed backwards for a distance of $10 \mathrm{~cm}$. On rectal examination, the tip could be felt through the mucosa of the anal canal, but no internal opening was seen. There was also induration to the left of the mid-line in the region of Cowper's gland.

Operation.-A sound was passed into the bladder and a solution of Bonney's blue was injected into the sinus. A circular incision was made around the opening of the sinus and this was continued posteriorly to the anal margin. The track was then displayed by dissection, which revealed a clearly-defined fistula passing backwards, lying on the perineal membrane, between the bulbo-spongiosus and ischio-cavernosus muscles (Fig. $1 a$ opposite).

The fistula communicated with the anal canal between the subcutaneous and superficial parts of the external anal sphincter, and with the ischio-rectal fossa by a blind extension. From the central part of the track, a further deep extension passed inwards. This appeared to pass parallel to the membranous part of the urethra, with which no communication could be found. The fistula, with its ramifications, was excised intact and the communication with the anal canal was opened by the division of the external sphincter and the lower part of the internal sphincter. The deep communication was cut across at the level of the perineal membrane. The wound was then allowed to heal by granulation.

Histological examination of the removed track revealed non-specific chronic inflammatory tissue in which plasma cells predominated. Haemosiderin-laden phagocytic cells were seen in the wall of the sinus, which was surrounded by much fibrosis.

Progress.-The patient was discharged from hospital 6 weeks after the operation, and when seen 3 months later was free from symptoms, with the wound completely healed.

Case 2, a man aged 59, attended the Out-Patient Department, complaining of "leakage of urine" from the perineum; 2 weeks previously he had had an abscess at the same site, which had started to discharge after 48 hours. Immediately after this, urine started to pass through the sinus during micturition. There were no other urinary symptoms, no difficulty or dysuria, and no evidence of urinary infection. One year previously he had had an abscess in the perineum which burst spontaneously, discharged sero-sanguinous material for about 3 weeks, and then cleared up.

There was a past history of epididymo-orchitis 16 years earlier, and an urethral discharge 9 years earlier, which subsided after treatment with a potassium citrate mixture. There had been intermittent non-specific urethral discharge for the previous few months.

Examination revealed a fit-looking man with no abnormality except the perineal fistula, which opened to the right of the mid-line about $2 \frac{1}{2}$ in. from the anus near the junction of the scrotum and perineum (Fig. 2). A probe could be passed backwards for only half an inch. Induration could be felt in the perineum passing towards the anus in the mid-line and, on digital rectal examination, a swelling could be felt in the region of the right Cowper's gland. During micturition, urine leaked from the external opening and a micturating urethrogram

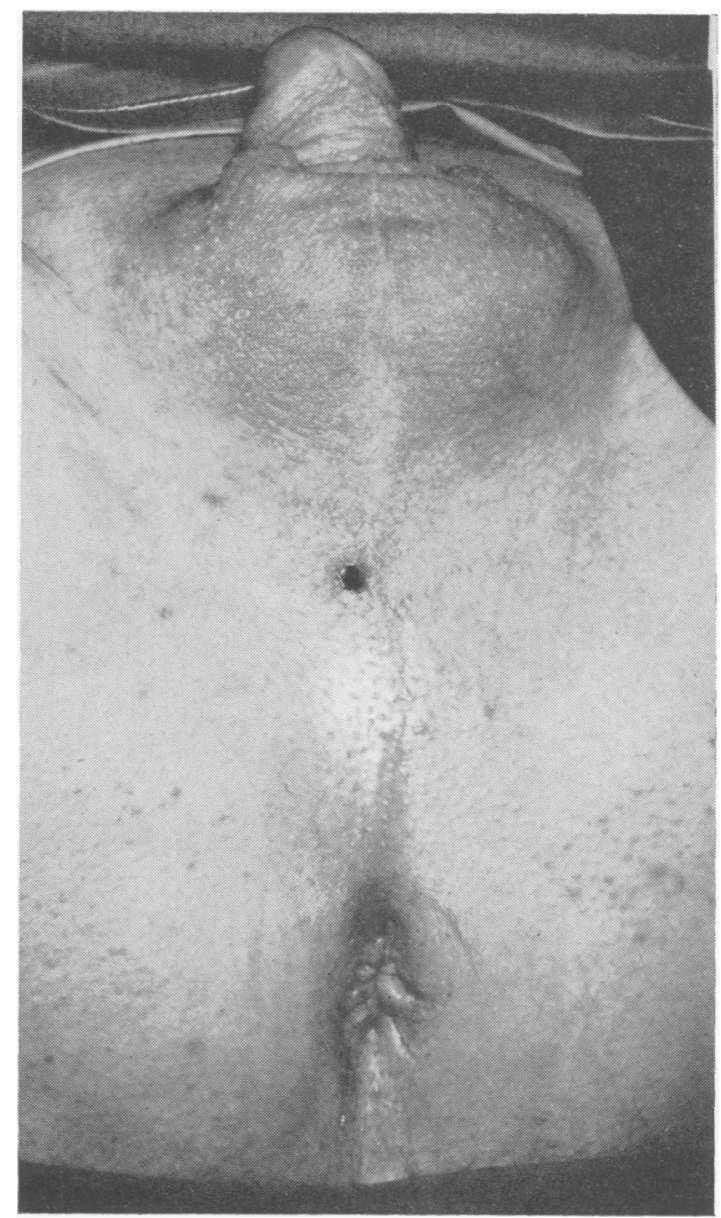

Fig. 2.-Position of external opening of fistula in Case 2, through which urine leaked, 
confirmed the presence of an urethral fistula (Fig. 3). The Wassermann reaction and Kahn and gonococcal complement-fixation tests were negative; a culture of the discharge have no growth of gonococci and a urine culture was sterile.

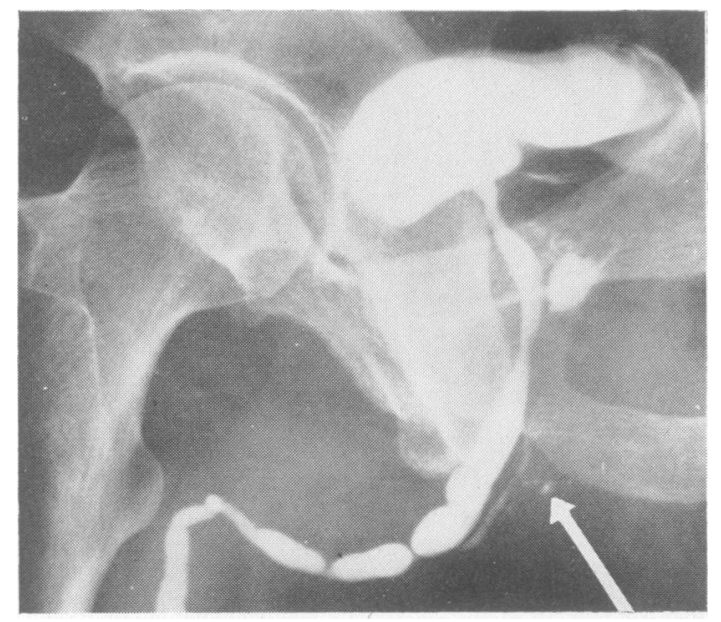
Fig. 3.-Micturating urethrogram of Case 2, showing urethral
fistula.

Operation.-Methylene blue was injected into the urethra and some was seen to come out of the external opening. An incision was made in the perineum, excising the opening of the tract. The superficial perineal pouch was dissected, and the tract was seen to be running superficial to the bulb of the penis and opening into the penile urethra about 3 in. from the base of the penis. The whole tract was excised.

The deep projection was seen to run to the left between the bulb of the penis and the ischio-cavernosus muscle, passing deep to the perineal membrane into the deep perineal pouch (Fig. $1 b$, p. 246). The perineal membrane was incised, and the abscess in Cowper's gland was curetted. The whole wound was laid open and allowed to granulate.

Progress.-The catheter was left in place for 3 days. There was no leakage of urine through the perineal wound post-operatively, and the wound healed satisfactorily. There was no difficulty in micturition, and the patient made an uneventful recovery. Three weeks later the wound was completely healed and there were no symptoms.

\section{Comment}

These are two patients with cowperitis, one giving a history of gonorrhoea and the other a history of non-gonococcal urethritis.

Acute infection of Cowper's gland, which is usually unilateral, is not frequently seen. When it does occur the gland may break down with abscess formation; this may not remain localized, but the pus may track down and present as a perineal abscess with sinus formation; on the other hand, spontaneous rupture of the abscess into the urethra may occur.

Routine digital palpation of the perineum for all patients having tests of cure for gonorrhoea and non-gonococcal urethritis occasionally reveals chronic enlargement of Cowper's glands, varying in size from a pea to a hazel nut. The follow-up of these chronic cases shows that they remain unchanged, with no signs of urethritis and with clear urine.

We wish to express our thanks to Sir James Paterson Ross and Mr. C. Naunton Morgan for permission to publish these cases. We are indebted to the Photographic Department of St. Bartholomew's Hospital for their help with the illustrations, to the Radiographic Department for the $x$ ray, and to Mr. A. Hitchins for the diagrams.

\section{REFERENCE}

Harkness, A. H. (1937). British Journal of Venereal Diseases, 13, 119 